\section{Spatio-Temporal Analysis of Early Printed Music using Interactive Maps - A Templating Approach}

GI_Forum 2018, Issue 2

Page: 72 - 84

Full Paper

Corresponding Author:

andrea.lindmayr-brandl@sbg.ac.at

DOI: 10.1553/giscience2018_02_s72

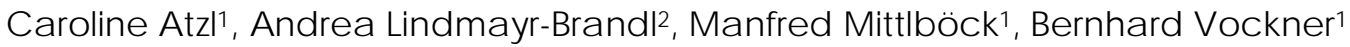 and Moritz Kelber ${ }^{2}$
}

${ }^{1 R S A}$ iSPAC E Salzburg, Austria

2University of Salzburg, Austria

\begin{abstract}
Spatio-temporal visualization tools a re powerful for communic ating and analysing spatial data as well as for generating new insights from this data. This applies not only to geography-related disciplines but also to other subjects. In this paper, we look at the results of a cross-domain cooperation between geoinformatics and musicology at Salzburg University. The a im is to develop a task-oriented, spatio-temporal web mapping solution to provide visual support for communicating and analysing the production of the first printed music in Geman-speaking countries from the 15th to the middle of the 16th centuries. The approach behind this interdisciplinary cooperation, the prototypical web maps as well as the results of a short exploratory online survey are introduced to assess how this spatiotemporal approach is evaluated by representatives of the musicology department. The paper also shows the added value of using spatio-temporal visualization methods to gain new insights into the world of early printed music.
\end{abstract}

\section{Keywords:}

web mapping templates, interactive maps, spatio-temporal maps, ea rly printed music

\section{Introduction}

Spatio-temporal data visualization is meaningful to structure and communicate data visually by providing information in a format that can be easily captured by human beings (Wang et al., 2017). Spatio-temporal visualization tools support the analysis of data and can help to gain new insights or make decisions. The information that is hidden within data especially (e.g. areas with a high rate of events, changes of these hotspots over time, relationships between hotspots) is of high interest for analysts (Lukasczyk et al., 2015). Goodchild (2013) mentioned that 'space and time frame all aspects of the discipline of geography' and that 'everything of relevance to geography occurs somewhere, at some time' (p. 1072). However, geography is not the only discipline in which spatio-temporal analysis of data is of central importance (Lukasczyk et al., 2015). 
Accordingly, we want to show how valuable interdisciplinary collaboration between different domains of science is, even when the connecting factors are not visible at first glance. Hence, we present results from the Austrian Science Foundation (FWF) project 'Early music printing in German-speaking lands: studies in technical and repertoire development (P28353G26)', where musicologists work together with specialists of applied geoinformatics to develop a spatio-temporal mapping solution for early printed music data.

Until recently, music printing in the German-speaking context has hardly been investigated (Lindmayr-Brandl et al., 2018; Lodes, 2010). The project comprises the collection, exploratory evaluation and presentation of early printed music in German-speaking countries from the period 1470-1550. This period is of high interest, (1) because of the technical shift in printing of music from multiple impression technique to single impression technique, (2) because of the start of the Reformation, when printed music was used for spreading political and theological propaganda, and (3) because polyphonic music was printed for the first time (Lindmayr-Brandl et al., 2018). Although the focus is on German-speaking countries, a broad approach is used, which includes all kinds of sources containing printed musical notation (e.g. liturgical books, tablatures of diverse instruments, polyphonic music, hymn books, etc.). This range of sources provides new insights into the production of music and the role of music printing in cultural history (Lindmayr-Brandl et al., 2018).

The complex open-access online database $v d m$ (Verzeichnis deutscher Musikfrühdrucke / Catalogue of early German printed music) was developed as part of the project, for organizing and querying the available early printed music data. However, the evaluation of the printed music using the graphical user interface (GUI) of the $v d m$ database reaches its limits when it comes to a central research question: the distribution of printed music in space and time.

The need for a spatio-temporal visualization of the distribution of early printed music is the 'connection point' between musicology and applied geoinformatics. In this cooperation, different interactive maps were developed using tools and know-how from the geoinformatics domain to visualize the space-time distribution of early printed music and thus make it tangible and understandable to a user group from a completely distinct domain (here musicology and scholars from book research). With the help of this tool, spatiotemporal developments of printing techniques can be conceived, centres of music printing detected, and the dissemination of specific source types appears in plain view.

The tools can be used in several ways. First, the web maps help to answer predefined questions with regard to the spatio-temporal distribution of printed music (e.g. 'Where are the hotspots of early printed music in German-speaking countries?'). Second, the tools can give users new insights from the data using the filter and query possibilities provided by the map app (e.g. the user may combine different categories to create his/her own complex queries). In addition, the tools visually help to verify or falsify specific hypotheses such as 'the centres of music printing spread from the southwestern corner to the northeast part of German-speaking countries'.

Mapping has changed over the past decade; today, far more maps are consumed in digital than in analogue form (Sack, 2018). If maps are used for visualizing spatial processes or events, then 'time is an inevitable dimension in order to understand the genesis of an event 
or a certain state of the universe of discourse' (Scholz \& Mittlböck, 2012). Currently, there is a trend of providing and using predefined web map templates for creating digital maps (e.g. ArcGIS Online Web App Templates, Web AppBuilder for ArcGIS, ESRI Story Maps, Web App Builder plugin for QGIS, Mapme, etc.). A web mapping template is a predefined and configurable web app that allows users to customize the appearance and behaviour of an app (Schwoppe, 2016). The idea behind the web map templating approach is to provide different layouts that can be customized without any coding, to be used for a wide area of applications (e.g. in browsers, on different mobile devices) while ensuring that cartographic design concepts and standards are implemented.

The templating approach is also used in our cross-domain cooperation to create the different interactive web maps that are based on the same web map template, while each is tailored to allow new insights from the data, answer certain research questions, or perform specific tasks ('one-task-one-app' philosophy; Scholz \& Mittlböck, 2012). Examples of research questions are 'Where and how quickly did early printed music spread in German-speaking countries?', 'In which areas of German-speaking countries has woodblock printing been used most frequently for music?' or 'To what extent did the Reformation promote the printing press, and where were the new printing centres (compare the year 1515 with 1530)?'.

To allow for such diverse questions, several interactive web maps were created (e.g. with different spatio-temporal filter operations, clustering functionality, heatmap, etc.) The web maps are all available via a card-based home page. The breakdown of the individual map contents according to thematic sorting or specific tasks, resulting in various mini-mapapplications, allowing users to focus on very precise and individual cartographic content (Mittlböck et al., 2012).

In this article, we describe this new cross-domain approach, present the technical workflow and some of the prototypical web maps, as well as discuss the results of a small exploratory online survey. The aim is to answer the research questions: 'How do representatives from musicology rate a "one-task-one-app" approach that uses web map templates for presenting early printed music data?'; 'Is there an "added value" to using a spatio-temporal mapping approach for early printed music?', and if so, 'What is the value added by using spatiotemporal interactive web maps for visualizing the early printed music data?'.

\section{The concept behind the cross-domain cooperation}

Until the start of this interdisciplinary cooperation, the working group of the musicology department used the open-access online database $v d m$, which was developed within the FWF project 'Early music printing in German-speaking lands: studies in technical and repertoire development (P24075-G23)' for analysing early printed music data. The $v d m$ is a regularly updated relational database that distinguishes between two levels, the 'edition level' for the abstract idea of the book, and the 'copy level' for the individual exemplars of the same edition (Lindmayr-Brandl, 2017). The two levels are linked with each other as well as to other relevant items if there is a relationship between them (Lindmayr-Brandl et al., 2018). The data acquisition is very detailed, oriented to specific research questions, and goes far beyond regular bibliographies. All printed music sources with any type of notation are of interest, so 
that a variety of different printing types and techniques are collected for the $v d m$ database. Currently, the $v d m$ database contains 1,192 editions and about 7,000 copies that are assigned to the relevant editions. However, the $v d m$ database reached its limits when it came to spatiotemporal research questions regarding the hotspots and the distribution of early printed music in space and time, giving rise to the desirability of interdisciplinary collaboration with geoinformatics. Together, we have developed various spatio-temporal web maps that follow a 'one-task-one-app' philosophy (see Section 'The one-task-one-app philosophy and the card-based design approach).

Figure 1 shows the technical workflow to extract the relevant data from the $v d m$ database and integrate them into the different web maps, which are the interactive tools that the user can run to obtain the results dynamically. The $v d m$ database contains various tables with a large number of attribute fields, but not all of the available data are necessary to answer a specific research question, develop new research questions from the visual analysis, or gain new insights from the underlying music print data. Therefore, specific database views (which we might think of as 'virtual tables') were created based on complex queries in order to extract only the information needed. Examples of some of the most important fields are title, printer, year of publication, publisher, type of source, confessional identity, printing technique, musical genre, number of voices, colour printing, language, type of notation, and longitude and latitude of the place of printing.

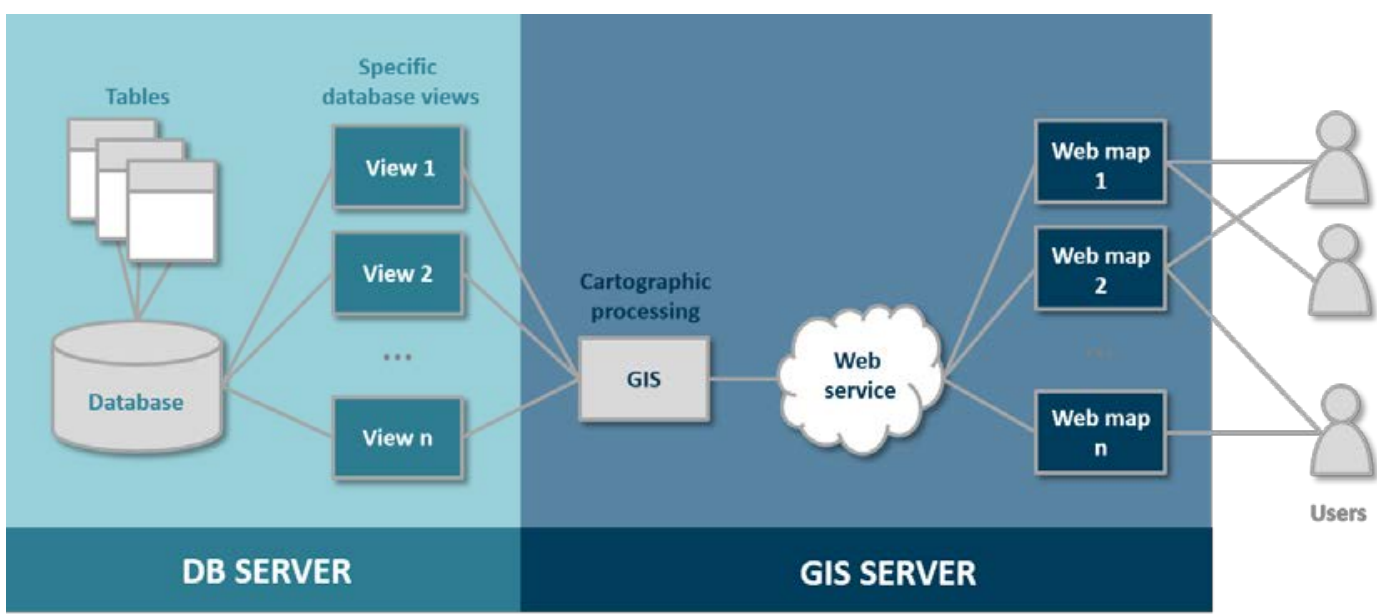

Figure 1: Technical workflow

In the next step, we integrated the database views in a GIS (in our case ESRI ArcGIS Desktop 10.6) by creating point features based on the coordinates (longitude and latitude fields). After further processing, we published the early printed music data as standardized web services (using ArcGIS Server 10.4.1). These web services are integrated into the different spatio-temporal web mapping prototypes using a templating approach (Web AppBuilder for ArcGIS).

As already stated, the spatio-temporal maps help to answer specific research questions as well as to gain new insights. Therefore, there are maps that provide simple, predefined 
filtering tools, as well as ones that allow users to define their own complex filters. Moreover, each map gives access to a time-slider tool, which allows the user to get information about the spatio-temporal distribution of the previously filtered data. The filter tools use single or multiple categories that are stored for each printed music dataset. The results of each executed query are dynamically calculated and shown on the map. The main categories used for the filters, concerning most research questions, are 'source type', 'confessional identity' of the print's content, 'printing technique' and 'format' of the print.

In the following section, the spatio-temporal mapping prototypes and their interactive tools are explained in more detail.

\section{Realization of the customized web mapping prototypes}

We used the wizard-based Web AppBuilder for ArcGIS to create the first functional web map applications. This allows the fast and relatively easy development of one's own web maps using as few resources as possible. The tool provides predefined layout templates that can be configured, e.g. to change colours, set texts and images/logos, use specific maps and map layers, or integrate and justify widgets (time-slider, filter, legend, attribute table, etc.). The templating approach enabled a relatively inexpensive and time-saving solution for this project, albeit, regarding the design and features, a somewhat limited one. Therefore, we performed several iterations to find out which web maps, widgets or tools are essential. The different interactive maps provide visual feedback on users' interactions and allow the graphical, spatio-temporal exploration of the early printed music data (e.g. filtering by year, printing technique, source type, confessional identity, or through the creation of complex queries). The integration of the time dimension in combination with the filtering and querying of the data enables new insights to be gained from the data regarding the spatiotemporal distribution of music prints (e.g. spatial patterns) and places with notably high numbers of occurrences (e.g. hotspots).

The various spatio-temporal web map prototypes are available via the home page, which uses a card-based design. This task-oriented access strategy as well as some of the prototypes are presented in the following two subsections.

\section{The one-task-one-app philosophy and the card-based design approach}

The communication strategy for presenting the different web maps follows a 'one-task-oneapp' philosophy, meaning that for each of the key tasks identified, a single web map is created. This task-oriented approach was presented and used by Scholz \& Mittlböck (2012) and is comparable with apps on smartphones. Scholz \& Mittlböck (2012) proposed that new users are less distracted thanks to the reduced amount of information and complexity, allowing them to focus on the task to be performed.

We therefore use a tile-based (or card-based) design, similar to the design strategy presented in Scholz \& Mittlböck (2012) and Mittlböck et al. (2012), to create an initial access point from which it is easy and fast to navigate to the right web map application (see Figure 2). 


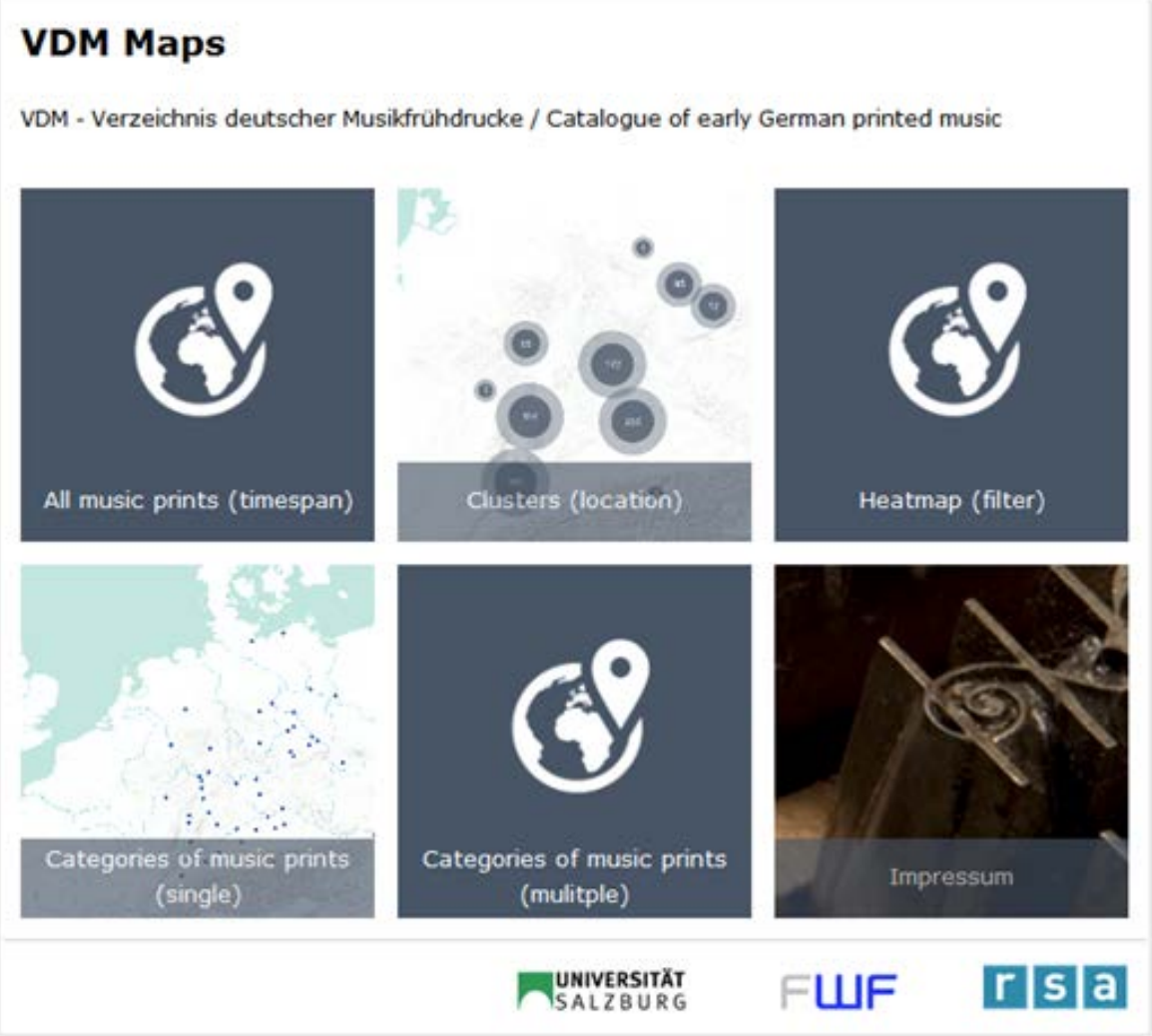

Figure 2: Initial home page for navigating to the different web maps

This card-based design is based on the design metaphor that Microsoft introduced with Windows 8, which is also used in many popular websites (e.g. pinterest, Google+). Cards are popular in web interfaces and mobile user interface designs and can have different shapes and colours, as well as consist of an image or use icons combined with a title or short text (Pal, 2016). We use this design approach for our cross-domain project because it is readily understandable, intuitive, well known, and helps users to quickly find the right web map.

\section{The spatio-temporal web mapping prototypes}

We developed five different web mapping prototypes during our interdisciplinary cooperation, using and configuring the templates provided by the Web AppBuilder for ArcGIS. A big advantage of using this tool is that the final web maps are rendered automatically, based on the screen size of the device (i.e. maps can be opened on a desktop PC, laptop, tablet or smartphone). Each of these web maps is created to fulfil a specific task and to answer some specific research questions based on the user's possibility to use simple or complex filters. All maps use the same layout (e.g. header, fonts, logos), standard map functionalities (e.g. address search, zoom in, zoom out, scalebar, legend, overview map), and an information window (including a short introduction and guidelines). Furthermore, a light 
basemap (ESRI terrain) shows just the most important rivers and place-name labels. Due to the widespread use of German in the 16th century, coverage is not restricted to the current German-speaking countries (Austria, Germany, Switzerland), but also territories outside them are included (Lindmayr-Brandl et al., 2018).

Summarized, the five web maps and their main tasks are as follows (cf. Figure 2):

- 'All music prints (timespan)': This interactive map shows the distribution and increase of all music prints between 1470 and 1550 based on a pre-calculated, time-enabled feature layer (sum of editions for each year). The available tools are the 'time-slider widget' for 'looping' through the data year by year and a very simple 'filter widget' to set the start year manually. This map allows the visualization, for a broader audience, of how the spatial spreading of early printed music has changed and developed over time.

- 'Heatmap (filter)': A heatmap is calculated automatically based on the music print data shown on the map (this depends on the time span set within the 'time-slider' widget). In addition to the time-slider, there is a simple group filter that can be used to filter the music prints per 'source type', 'confessional identity' or 'printing technique' (see Figure 3). These three attributes in combination with each other are of special interest for musicological research because they reveal information about distribution and clustering over time.

- 'Categories of music prints (single)': This map is similar to the 'Heatmap (filter)' map, with the difference that each music print is shown only as a single point on the map (with no heatmap or clustering).

- 'Clusters (location)': In this map, which allows even deeper insights into the data, users can use the 'sum widget' to calculate dynamic clusters depending on the zoom-level and map extent (the number of music prints per cluster is shown in the middle of each cluster). In addition, it is possible for users to create their own complex filters. These can use any of the available categories, such as only show clusters for post-1500 hymn books of Lutheran confession in $8^{\circ}$ or $4^{\circ}$ format using woodcuts.

- 'Categories of music prints (multiple)': This map is similar to the 'Clusters (location)' map, with the difference that each music print is shown as a single point on the map (with no heatmap or clustering). This web map is primarily for advanced users who are familiar with the music print data and can create complex filters (see Figure 4). As a result, the user is able to derive new research questions from the data.

The five web maps help to gain an impression of the geographical dispersion of the music prints over time and reveal the printing centres based on the cumulative number of editions printed in each place for a specific year. The possibility of setting simple and complex filters further enhances the spatio-temporal analysis of the early printed music. For example, through the use of the web map 'All music prints', one can easily recognize that the centre of music printing in the first decade of the 16th century lies in the southwestern corner of the German-speaking territories and spreads along the Rhine and Danube (Lindmayr-Brandl et al., 2018). Up to 1550 , the map changes continually and the number of editions produced in the existing print centres (i.e. Strasbourg, Augsburg, Nuremberg, Leipzig, Wittenberg) increases significantly, while new centres of printing also appear on the map (LindmayrBrandl et al., 2018). 

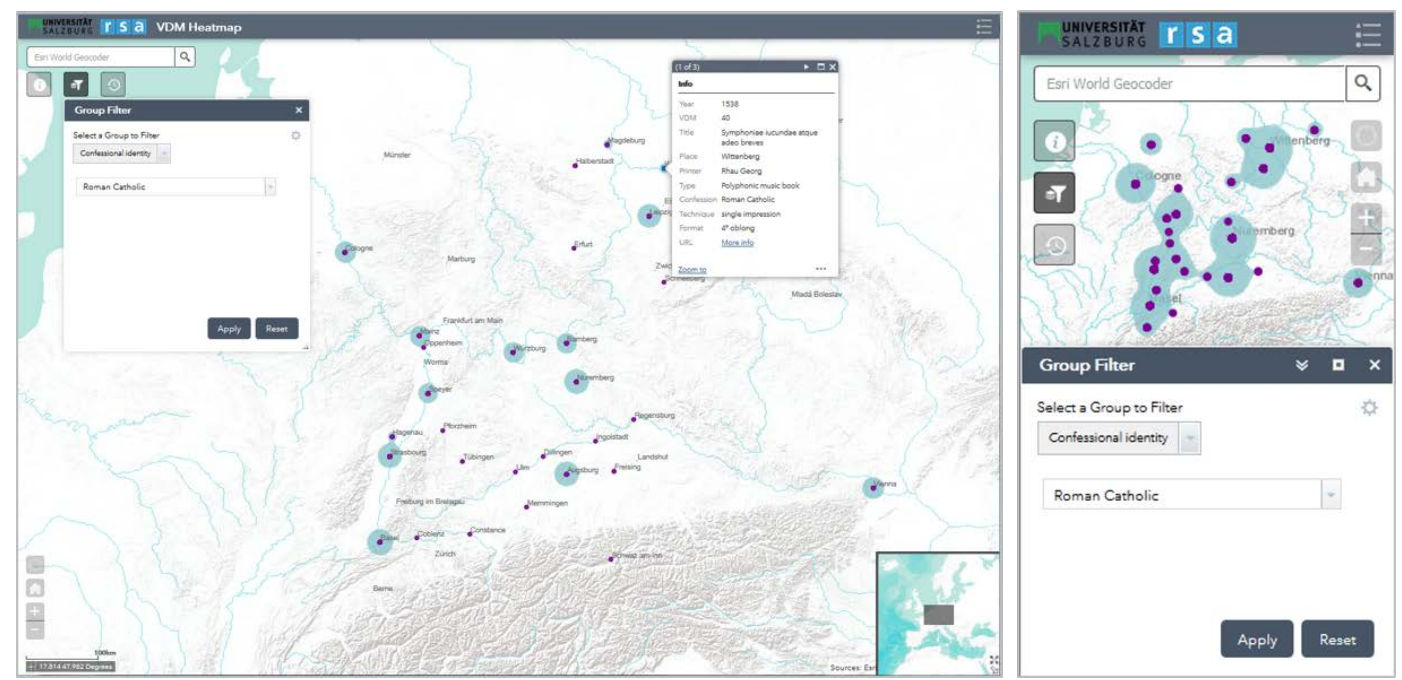

Figure 3: 'Heatmap (filter)' app on a Desktop PC (left) and on a smartphone (right) with the simple group filter opened showing music prints for Roman Catholic confession only
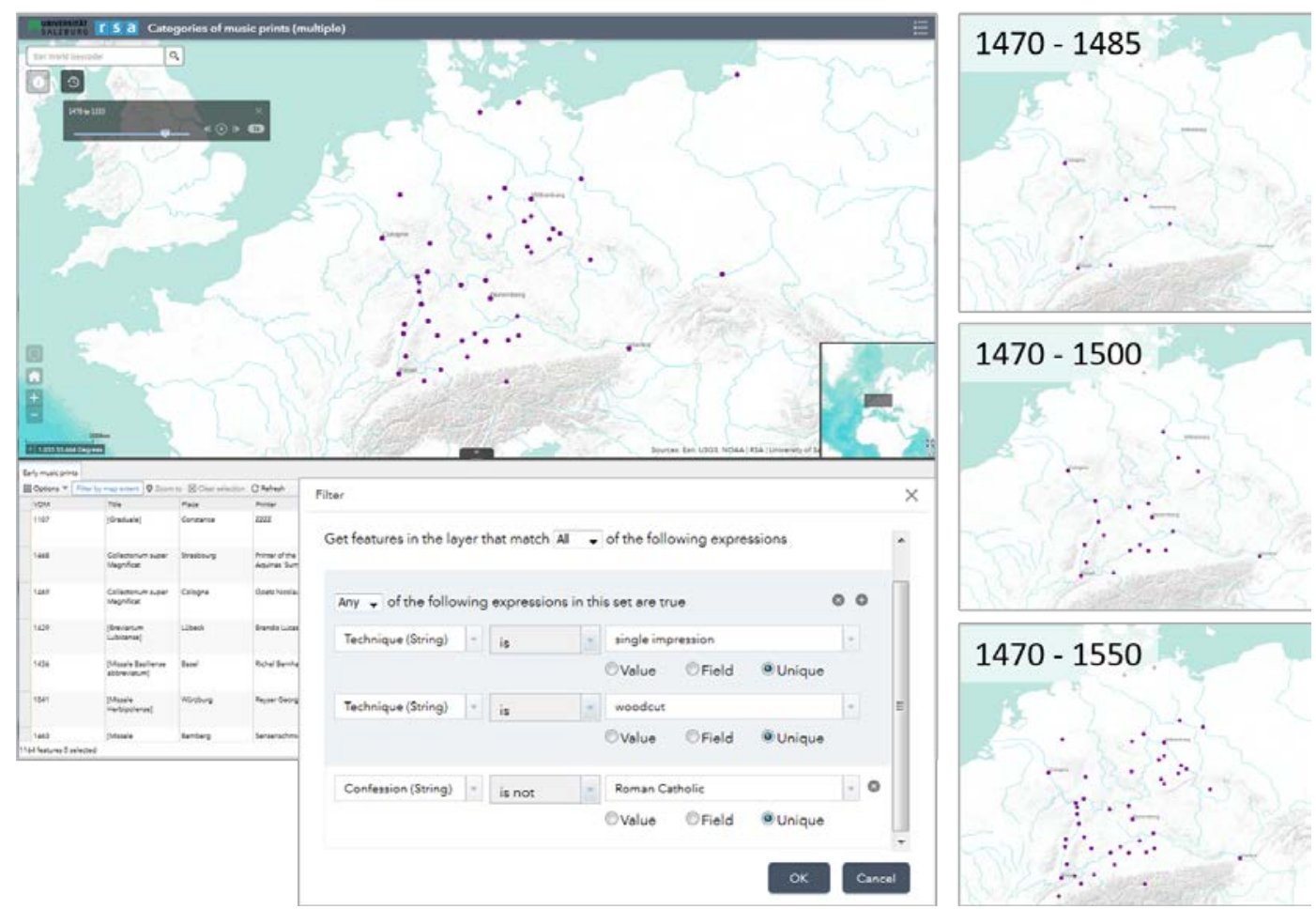

$1470-1550$

Figure 4: 'Categories of music prints (multiple)' app showing the time-slider and the attribute table, as well as a complex filter for music prints using a single impression or woodcut printing technique and where the confession is not Roman Catholic (left). On the right are three screenshots showing different time spans, illustrating the distribution of these filtered music prints over time. 


\section{First results derived from the web mapping prototypes}

Based on the two map queries shown in Figures 3 and 4, we show an example of how new insights can be gained from early printed music data. The maps address the synergy between the Reformation and the emerging printing industry, which is one of the main focuses of the project 'Early music printing in German-speaking lands'. Figure 3 shows Roman Catholic prints only (simple query), while Figure 4 displays Non-Roman Catholic prints combined with typical printing techniques (complex query). Based on the interactive web map related to the snapshot shown in Figure 3 (and using the time-slider), the user may form the hypothesis that from the 1520 s the production of early printed music of Roman Catholic confession declined noticeably, both in absolute number and in spatial distribution. This insight is especially significant as it challenges the well-established theory that the Reformation fostered print in general, and also the print production of the opponents of the Reformation (Pettegree \& Hall, 2004). However, this first impression has to be further validated.

Based on maps that visualize the development of non-Catholic music prints (see Figure 4, here combined with typical printing techniques), users can see that at the start of the Reformation movement, music printing was not the primary focus of the Lutheran supporters. At this time, the printing shops were fully occupied publishing treatises and broadsheets to reach a broad readership interested in the fierce discussions between the two hostile parties. However, the maps show that when Lutheranism became established in specific locations, many German cities again started producing specific source types, such as hymn books or liturgical books (Kirchenordnungen), that included music.

These examples show that maps are powerful tools for analysing data in a spatio-temporal manner, even across different domains and disciplines.

\section{User perception of the one-task-one-app approach and the spatio- temporal map prototypes}

We conducted an online questionnaire to obtain an exploratory evaluation of our 'one-taskone-app' approach, the different spatio-temporal web maps, the card-based design approach for accessing the maps, as well as to find out more about the added value of presenting early printed music in web maps. We prepared a Google Forms survey that comprised ten questions and a short general section (e.g. gender, age) that took about 5-10 minutes to complete. The link to this online questionnaire was distributed within the music and dance research department (including project members and students from courses or workshops). 18 people took part, 12 of whom were female and 6 male. Not everybody answered all of the questions; the survey was completely anonymous.

The first section of the survey included questions regarding previous experiences with web maps and their range of applications. Google Maps was the most-mentioned web mapping service: 17 participants use Google Maps frequently; the remaining participant uses it rarely. Other web mapping services (e.g. Bing Maps, Yahoo Maps, Here WeGo, OpenStreetMap) are frequently used by 2 participants only; rarely by 5; and 10 never use them. All 18 
participants use web maps for navigation, 11 to explore places virtually (e.g. using Google Earth), 9 to record GPS/GNSS tracks, and 5 to visualize spatial data.

Another section of the questionnaire comprised questions regarding the usefulness of the card-based design approach. 15 participants stated that the card-based home page is 'very useful' or 'fairly useful'; 3 graded it 'not very useful' or 'not useful at all'. 15 of the participants liked the 'one-task-one-app' philosophy, the clear and quick navigation to the different web maps, and the use of descriptive icons. The card-based design, which is similar to the Microsoft Windows tiles, was liked by 11; 7 didn't like this design idea. 16 participants thought it was a good idea to have a home page.

The overall appearance of the different dynamic web mapping prototypes was rated 'very good' by 3 participants, 'fairly good' by 12 , 'not very good' by 2 , and 1 participant rated them as 'not good at all'. Figure 5 shows the results of the evaluation of the web map layout and design. 14 of the participants liked the colours used for the elements (e.g. header, buttons), and 16 the colours of the map content (e.g. music printing layer, heatmap layer). 7 of the participants did not like the size of the elements (e.g. buttons, header, windows), and 6 were not satisfied with the size of the music print points. The arrangement of the buttons was liked by 16 participants, and for 12 of them the icons on these buttons were suitable. The overall layout and arrangement of the elements on the map (menu, windows, header) was approved of by 14 participants. Participants' additional comments included that it would be good to use warmer colours (1 participant), to use bigger point symbols for the music prints ( 2 participants), to alter the size of the point symbols depending on the zoom level (2 participants), to use bigger buttons (1 participant), to integrate the widget-buttons into the header ( 1 participant), and that the information window is very important and its content well written (1 participant).

\section{Evaluation of the spatio-temporal web maps (layout and design)}

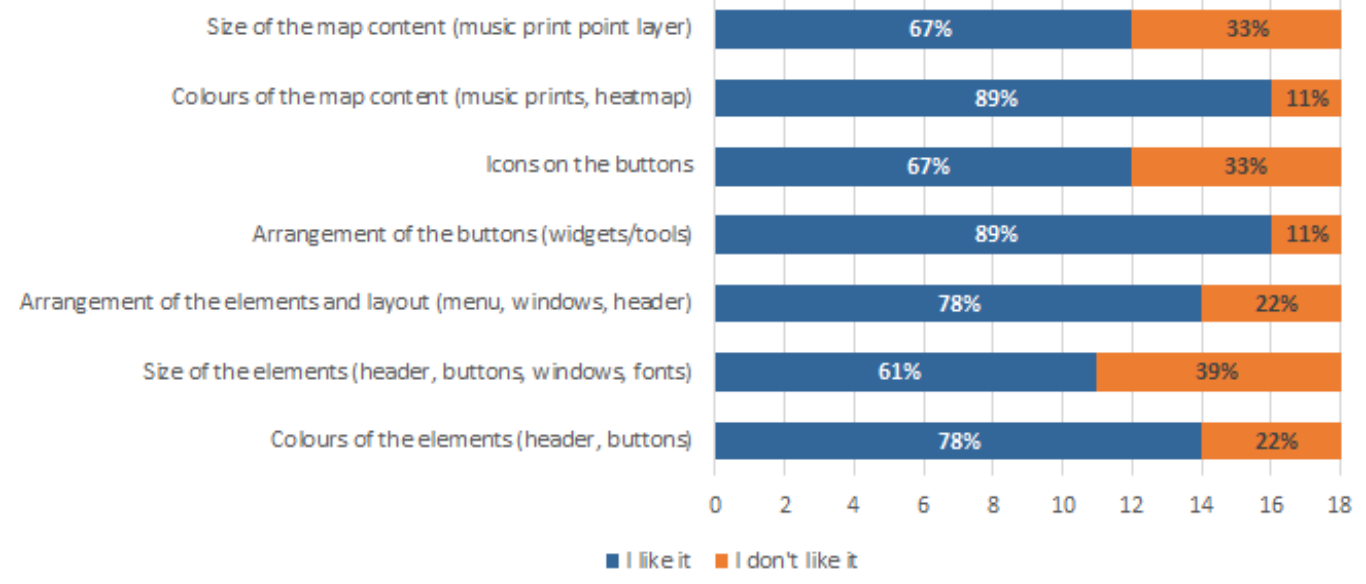

Figure 5: Evaluation of the design and layout of the spatio-temporal web mapping prototypes [ $=18]$ 
To the question about the coherence and understandability of the available widgets/tools (e.g. time-slider, calculate clusters, set filter) within the different web maps, the answer 'very easy to understand' appeared 5 times, 'fairly easy to understand' 10 times, and 'not understandable' is mentioned twice. For 16 of the 18 participants, navigation within the map was easy and intuitive. 13 participants said that the information window contained important descriptions and content, and only 4 did not agree with this.

Nearly all of the participants (17) are convinced that there is a high or at least fairly high added value gained through the spatio-temporal map visualizations of the early printed music (see Figure 6).
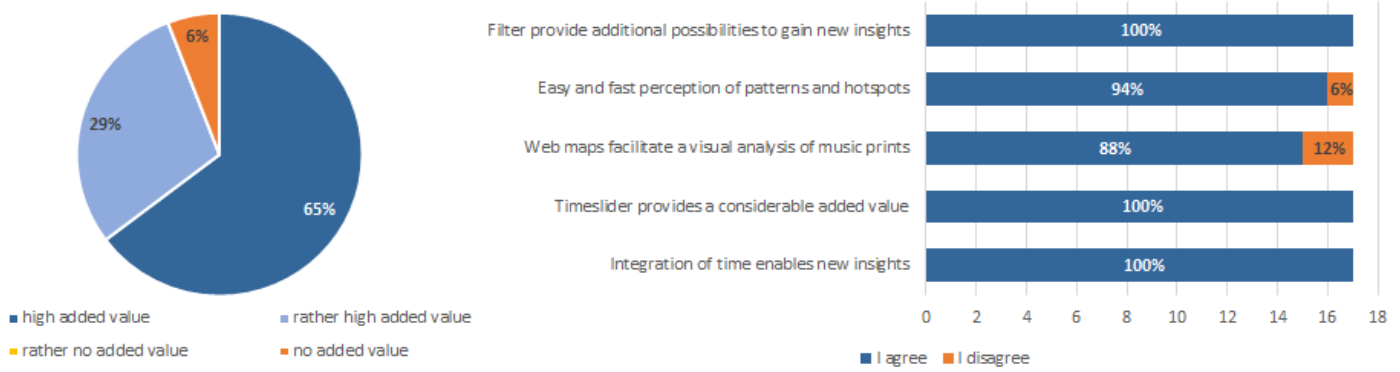

Figure 6: Evaluation of the design and layout of the spatio-temporal web mapping prototypes [ $n=17]$

All participants agreed that the integration of time allows new insights to emerge from the music print data. Likewise, all mentioned that the time-slider provides a considerable added value (e.g. through the animated visualization of the early printed music spreading over space and time). 15 participants agreed that the visualization of early printed music in the form of web maps facilitates the visual analysis of the data; 2 participants disagreed with this statement. 17 stated that the spatio-temporal web maps enable users to see hotspots and patterns within the music print data quickly. All participants stated that filters provide additional possibilities for further new insights (e.g. by analysing only subsets of the data, such as specific source types, printing techniques and/or confessional identities).

\section{Discussion and outlook}

The spatio-temporal interactive maps presented here provide meaningful support for analysing the development and distribution of early printed music, to answer specific research questions, and to gain new insights from the data. Questions that can be answered using the map prototypes include, "Where are the centres of early printed music in Germanspeaking countries?' and 'How did the centres of music printing spread over time?'. These questions can be further broken down using simple or complex filters for specific categories (e.g. only show music prints with Roman Catholic confession and/or music prints where woodblock printing is used). The integration of the time dimension is thus inevitable for the 
presentation of early printed music and their spatial spread in German-speaking countries during the 15th century and first half of the 16th century. Time-enabled interactive web maps are particularly meaningful tools, especially for visual analysis of patterns and hotspots. This is also shown by the results of the exploratory survey that was conducted with 18 participants from the musicology department of the University of Salzburg (see Section 3). To sum up, the 'one-task-one-app' principle was well received and liked by 15 participants. The idea of having a home page was meaningful for 16 participants. Almost all participants (15) agreed that the spatio-temporal visualization of early printed music in the form of interactive web maps provided a considerable added value for them.

In general, the survey showed that when many similar maps are required using as few resources as possible, as in our case, the use of predefined and configurable web mapping templates is excellent. Despite the restrictions in map design and functionality, we were able to achieve good and satisfying results with the templating approach. We are aware that 18 is a small number of participants, but currently only a small group of students and project members have access to these web maps. However, the first results of this exploratory survey show that there is a need for spatio-temporal mapping visualizations in the scientific discipline of musicology, and that these visualizations provide new insights into historical data (such as that from 1520 onwards, the production of early printed music of Catholic confession declined noticeably; see Section 3).

This finding challenges the well-established theory that the Reformation fostered print in general (including the print production of the opponents of the Reformation). Further, the analysis shows that music printing was not the primary focus of the Lutheran supporters at the beginning of the Reformation, and that many German cities later again started to print specific source types (e.g. hymn books or liturgical books) that included music. These are first insights that have to be investigated in the future. A further common project between geoinformatics and musicology is planned that will build on the results presented in this article. The idea is to enhance and expand the current spatio-temporal web maps in order to facilitate additional insights, and to make the results and maps available for the wider public.

\section{Acknowledgement}

This research work is part of the FWF project 'Early music printing in German-speaking lands: From the 1470s to the mid-16th century (P28353-G26)'.

\section{References}

Goodchild, M. F. (2013). Prospects for a Space-Time GIS. Annals of the Association of American Geographers, 103(5), 1072-1077. doi:10.1080/00045608.2013.792175

Lindmayr-Brandl, A., Giselbrecht, E., \& McDonald, G. (Eds.). (2018). Early Music Printing in GermanSpeaking Lands. London \& New York: Routledge.

Lindmayr-Brandl, A. (2017). Early Music Prints and New Technology: Variants and Variant Editions. Fontes Artis Musicae, 64, 244-60. 
Lodes, B. (Ed.). (2010). Niveau Nische Nimbus. Die Anfänge des Musikdrucks nördlich der Alpen. Wiener Forum für ältere Musikgeschichte 3, Tutzing: Schneider.

Lukasczyk, J., Maciejewski, R., Garth, C., \& Hagen, H. (2015). Understanding Hotspots: A Topological Visual Analytics Approach. The 23rd SIGSPATIAL International Conference, 1-10. doi:10.1145/2820783.2820817

Mittlböck, M., Morper-Busch, L., Atzl, C., \& Klug, H. (2012). Task-orientierte Web-Maps zur kompakten Visualisierung kartographischer Inhalte. In Strobl, J., Blaschke, T., \& Griesebner, G. (Eds.), Angewandte Geoinformatik 2012. Heidelberg: Wichmann Verlag, 333-338.

Pal, P. (2016). How Card-Based Design Is Changing Web \& Mobile UI Designing? Retrieved from https://think360studio.com/how-card-based-design-is-changing-web-mobile-ui-design/

Pettegree, A., \& Hall, M. (2004). The Reformation and the Book: A Reconsideration.The Historical Journal, 47(4), 785-808.

Sack, C. (2018). The Status of Web Mapping in North American Higher Education. Cartographic Perspectives, 25-43. Retrieved from http://www.cartographicperspectives.org/index.php/journal/article/view/1429/1617

Scholz, J., \& Mittlböck, M. (2012). Spatio-temporal Visualization of Simulation Results using a task-oriented tile-based Design-Metaphor. In: Jobst, M. (Ed.), Service Oriented Mapping 2012. Jobstmedia Management Verlag, 369-382.

Schwoppe, S. (2016). Getting the most out of ArcGIS Web App Templates. Retrieved from http://proceedings.esri.com/library/userconf/fed16/papers/fed_67.pdf

Wang, D., Guo, D., \& Zhang, H. (2017). Spatial Temporal Data Visualization In Emergency

Management: A view from data-driven decision. Proceedings of the $3 \mathrm{rd}$ ACM SIGSPATIAL Workshop on Emergency Management using (EM-GIS'17). New York, USA: ACM. doi:10.1145/3152465.3152473 